\title{
Article
}

\section{Munchausen by Proxy: A Qualitative Investigation into Online Perceptions of Medical Child Abuse}

\author{
Anderson, Anoushka P.A, Feldman, M.D and Bryce, Joanne \\ Available at https://clok.uclan.ac.uk/19497/ \\ Anderson, Anoushka P.A, Feldman, M.D and Bryce, Joanne orcid iconORCID: \\ 0000-0001-9144-2899 (2018) Munchausen by Proxy: A Qualitative \\ Investigation into Online Perceptions of Medical Child Abuse. Journal of \\ Forensic Sciences, 63 (3). pp. 771-775. ISSN 0022-1198
}

It is advisable to refer to the publisher's version if you intend to cite from the work. http://dx.doi.org/10.1111/1556-4029.13610

For more information about UCLan's research in this area go to http://www.uclan.ac.uk/researchgroups/ and search for <name of research Group>.

For information about Research generally at UCLan please go to http://www.uclan.ac.uk/research/

All outputs in CLoK are protected by Intellectual Property Rights law, including Copyright law. Copyright, IPR and Moral Rights for the works on this site are retained by the individual authors and/or other copyright owners. Terms and conditions for use of this material are defined in the policies page.

\section{CLoK}

Central Lancashire online Knowledge www.clok.uclan.ac.uk

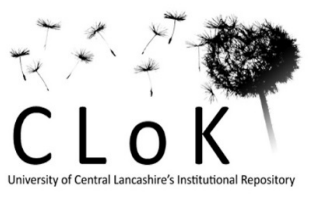


Online perceptions of medical child abuse

Munchausen by Proxy: A Qualitative Investigation into Online Perceptions of Medical Child Abuse

Anoushka P.A. Anderson, ${ }^{1}$ M.Sc.; Marc D. Feldman, ${ }^{2}$ M.D.; and Joanna Bryce, ${ }^{1}$ Ph.D.

${ }^{1}$ School of Psychology, University of Central Lancashire, Preston, United Kingdom.

${ }^{2}$ Department of Psychiatry, University of Alabama, Tuscaloosa, AL. 
Online perceptions of medical child abuse

ABSTRACT: In Munchausen by proxy (MBP) maltreatment, increasingly termed "medical child abuse" (MCA), a caregiver fabricates or induces illness in another. The perpetrator's goal for the behavior is to meet personal emotional needs by forcing unnecessary or misguided medical or psychological treatment. Generally, a mother is the perpetrator and her child is the victim. There is a serious lack of research into most aspects of MCA, and the current study is the first to utilize the anonymity of an Internet forum to investigate victims' first-hand experiences of, and the public's opinions about, suspected and confirmed MCA. Three-hundred and fifty-six posts by 348 members were explored and coded using formal qualitative content analysis. By accessing an open-thought online forum, the current paper acquired information regarding social perceptions about the nonperpetrating partners who are unaware of the maltreatment; the disturbing and counterintuitive phenomenon of MCA itself; and the resistance often faced by those who attempt to report it.

KEYWORDS: forensic science, medical child abuse, online perceptions, Munchausen by proxy, qualitative research, non-perpetrating partners, Internet research, factitious disorder 
Online perceptions of medical child abuse

Among the most daunting forms of abuse and/or neglect is Munchausen by proxy (MBP) maltreatment. MBP, termed "factitious disorder imposed on another" in the Diagnostic and Statistical Manual of Mental Disorders, Fifth Edition(DSM-5), (1), is increasingly called "medical child abuse" (MCA). It is uncommon compared to overt physical or sexual abuse, and remains understudied. In typical cases of MCA, a caregiver (generally the mother) intentionally produces the appearance of, or induces, illness in another person. The usual victims are infants and toddlers who are too young to verbally communicate the maltreatment they are enduring. The main ailments and medical signs that are fabricated or induced include apnea, seizures, bloody stools, vomiting, rashes, dehydration, fevers, lethargy, and even cardiopulmonary arrest (2). Studies of published cases have shown that the mortality rate of victims of MCA is between 6 and 10 percent, making it perhaps the most lethal form of child abuse (2).

The perpetrators present themselves as seemingly caring, loving, and devoted, and they usually engage in the maltreatment without the knowledge of others. There are documented cases from over 20 countries that demonstrate that MCA is not a pattern of behavior confined to Western societies (2), but rather is a behavior that constitutes a specific type of maltreatment. The prevalence of MCA is higher in tertiary care settings; indeed, a study at the Massachusetts General Hospital in Boston found that one-third of 155 infants who suffered repeated apparent life-threatening events were in fact victims of MCA (3).

Despite a general improvement in awareness of MCA, major facets - such as the prevalence rate, course, and long-term victim impact - remain unsettled (4). The initial disbelief among many medical professionals and family members that such abuse occurs has clouded the scientific effort of gathering information (5). Healthcare providers and families find it difficult to believe that a mother would intentionally hurt or even kill her own offspring, as most mothers work to ensure that their children are safe from harm (5).

Behind closed doors, perpetrators of MBP tend to see their children as "objects" rather than individuals with their own rights and feelings. Indeed, they may be more concerned about how the 
Online perceptions of medical child abuse

hospital staff and others view them, rather than their children (4). One of the most astounding characteristics is that perpetrators usually flourish in the hospital environment, appearing to gain enjoyment from the attention and admiration they receive for what appears to be exemplary mothering (6). All too often, hospital personnel become unwitting participants in the abuse. They perform multiple tests and procedures aimed at diagnosing illusory problems and often succumb to the medical preferences of the mothers (4). Interestingly, when a male figure attempts to develop such relationships with professional, they are perceived as overbearing or too demanding (7). Male perpetrators also differ in that they tend to tout their own accomplishments in interactions with staff, pointing to instances of perceived heroism in saving a child (8). Usually, healthcare professionals do not suspect mothers because they present as conforming to societal view of mothers as the epitome of concern (9). The perpetrator is under constant pressure to mask the life-endangering child abuse in which she is engaged, in a process termed "mother imposturing" (10).

Denial of the capability of women to commit heinous crimes including MCA may provide an explanation for the lack of research. This inability to accept that women are capable of perpetrating serious abuse, offers an explanation as to why prevalence rates may be higher than current estimates indicate. Furthermore, allowing child victims to develop into adulthood without suitable intervention increases the likelihood of a victim becoming a perpetrator.

Several observations can be made about non-perpetrating fathers in MCA cases. They present as having a passive role in the family dynamics. Non-perpetrating fathers rarely attend hospital visits, describing their role as that of a "traditional breadwinner" and leaving the care and nurturing to the mother (2). Most fathers appeared oblivious to both the partner's abuse and the specific details of the child's apparent illness (4). Often, the fathers become facilitators of the abuse by paying medical bills and not asking for details about the apparent illness (7).

The current research was designed to meld the studies of MCA and social networking. To do so, we investigated an open-thought discussion on an Internet forum for viewers of a televised show about MCA and its survivors. All the posts during and following the airing of the program were included in the analysis and a qualitative analysis was performed. A qualitative research design is 
Online perceptions of medical child abuse

usually appropriate when existing theory or research literature on a phenomenon is limited, as in the case of MCA. For a variety of reasons, the primary researcher (APAA) decided not to conduct a standardized survey to find information on the research questions. As MCA is under-investigated and yet illegal, finding potential participants - either perpetrators or victims - would be difficult. A purely qualitative research design was adopted because of its accompanying features: (i) developing a contextual understanding, (ii) adopting an interpretive stance, and (iii) understanding the processes through which interactions take place among individuals. The current paper intends to add to the literature on MCA by investigating four principal areas.

1: Diagnostic difficulties.

2: Non-perpetrating partners.

3: Long-term victim outcomes.

4: Social perceptions on motivation and perpetrator justice.

\section{Method}

The Research Sample

The forum chosen for analysis was the online community attached to a high-profile television show hosted by Dr. Phil McGraw ("Dr. Phil”). The show included discussions with both MCA perpetrators and survivors. The show was originally aired in the U.S. in 2007 and ran for 52 minutes. During and after the program, there were 356 comments made on the forum thread from 348 different usernames. The comments included 49,602 words, all of which were included in the analysis to ensure completeness. All comments quoted in the research were taken verbatim and not altered to comply with grammatical rules and accurate spelling. The programme forum chosen for analysis was created in 2007, with comments being posted up until late 2010. Although this was produced significantly earlier than the research conducted, due to the nature of the research and the lack of other research, it was decided that opinions on the topic would not have changed significantly in that time, making the research forum still valid. 
Online perceptions of medical child abuse

\section{Data Collection Methods}

Phase 1: Concept Coding

The first cycle of qualitative analysis conducted was Concept Coding. Concept Coding works by applying a series of codes and categories to the data to establish the overall meaning of a piece of text (12). This was used in this project to investigate data in terms of the accuracy of suspected but previously unreported cases of MCA.

\section{Phase 2: Affective Coding}

The second cycle of coding was Affective Coding, implemented to investigate human experience--including emotions, values, and judgments. The two types of coding under this umbrella term was Emotion Coding and Values Coding. Emotion Coding was used to investigate the social perceptions surrounding MCA. Values Coding facilitated the research on non-perpetrating fathers and their roles within the family network.

\section{Phase 3: Pattern Coding}

For the third cycle of coding, the technique of Pattern Coding was adopted. This type of coding allowed for the condensing of large sections of data and the subsequent development of major themes (13). As the final cycle of coding, this phase also allowed for Phases One and Two to be condensed into sections relevant to the research areas. This consolidation was completed using a Coding and Qualitative Data Analysis System (CAQDAS) - in this instance, ATLAS.ti - that permitted a computerized analysis of the data. The data were efficiently stored, organized, managed, and configured to enable analytic reflection and the discovery of the main concepts and themes.

\section{Analysis and Synthesis}

The formal process of data analysis began with the assignment of alphanumeric codes to the data, in accordance with the categories of the study. Large chart sheets were prepared that were colorcoded; each sheet identified the descriptors found within the research statements. As the process of coding the text progressed, new sheets were added and descriptors elaborated upon. This in turn 
Online perceptions of medical child abuse

became the coding manual. Once manual coding had been performed, randomized sections of text were presented along with the coding manual to three external individuals, to ensure consistency.

The third cycle of analysis not only facilitated the production of detailed summaries and the capture of key sections of the data, but also established several patterns and themes, based on either similarity or divergence. This analysis allowed the formation of a three-layer process in analyzing the data. First, patterns were examined and compared within categories relating to the coding manual. Second, these patterns were compared to find connecting threads. Finally, the findings were assessed for how they related to the previous literature (or lack thereof), helping to establish the broader implications of the research.

\section{Ethical Considerations}

Ethical approval was obtained from the University of Central Lancashire's Ethics Committee. Due to the focus on Internet-mediated information, gaining permission from the authors of the forum was not required. Data for the current research were collected from open-access discussion forums; no accounts or log-in procedures were required, and all usernames were kept anonymous to prevent the recognition of participants.

\section{Results}

\section{Diagnostic Difficulties}

The forum contained thirty-seven self-reported cases of MCA, of which nine were reports from family members or survivors of situations where a mother had been formally documented as having engaged in MCA. Many self-reported cases came from family members who suspected someone of engaging in MCA, or from a survivor of childhood abuse who believed that the criteria for MCA fitted the actions of a parent. Almost all these individuals made multiple attempts to contact social services or the police with their suspicions. Each time, they were dismissed, highlighting a need for professionals in all disciplines to be more aware of MCA. 
Online perceptions of medical child abuse

We sought the help of a counsellor... my mother-in-law railroaded the whole session, sprouting some amazing lies and cover-ups.

Thus, these individuals sought help in the form of online support. The ability to be able to connect with others who have had similar experiences can allow someone to feel less isolated, especially if they have not previously been believed about abuse (14).

I've reported these things to Protective services and the courts... Officials did not pursue it any further. No one has reviewed past medical records looking for inconsistencies.

All of the suspected cases of MCA presented types of behaviour that they experienced from the perpetrator.

I have seen her grab the children, point and poke at their eyes, pull their eyelashes... They have been treated for false mental disorders, ADHD, breathing difficulty, strep throat, ear infections.

The research mirrored previous findings regarding the difficulty of getting an official diagnosis of MCA (7). There is often immense difficulty faced by individuals who suspect someone of perpetrating MCA.

The perpetrator is too convincing. She has fooled every kind of expert you can imagine.

\section{Non-perpetrating Partners}

The most prominent finding of the current research is the clear absence of the father in the cases presented. There were several comments from survivors of MCA stating that the fathers were emotionally absent, acting more as traditional breadwinners, which mirrors previous research (15). 
Online perceptions of medical child abuse

In most situations they let the mother take care of the children's well being...as the father is involved in work.

Other stories from survivors stated that the fathers often "blindly" believed the untruths the mothers would offer them and would very rarely, if ever, attend medical appointments themselves.

My father was working every single day to keep food on the table. My father trusted everything my mother said, he was never involved in the doctor's visits. My father honestly didn't know.

The research addressed the potential connection between the emotionally absent fathers and the reasons for the mother perpetrating abuse. Despite living together, there was evidence of serious marital problems. These difficulties offer insight into the reasons that a mother would turn to MCA.

This could be a sick attempt to get attention from the children's absent fathers as well.

When a child or other family member is sick, parents typically come together. Mothers who perpetrate MCA may find that the child's being unwell can provide a reprieve in the existing marital conflict, which in turn becomes a pattern of trying to re-engage a spouse into family life (16). Many commenters who were not the victims of abuse portrayed negative views about the fathers, believing they should be held accountable for their ignorance. However, all the victimized individuals in the current research offered practical explanations as to why their fathers did not notice. This finding parallels previous research that has shown that victims of MCA generally absolve the nonperpetrating parent of responsibility (17). 
Online perceptions of medical child abuse

The current research failed to allow for an in-depth discussion of the long-term outcomes for survivors. Unfortunately, only one individual commented on the psychological consequences of being a survivor of MCA. This person stated that he suffered from posttraumatic stress disorder as a result of the abuse he experienced as a child, in line with the observations of Libow (17).

I'm trying very hard to deal with the abuse (I suffer from PTSD because of this).

\section{Social Perceptions}

The research showed that the term "Munchausen by proxy" may minimize the impact on the victim. The term is a diagnosis applied to the perpetrator, and individuals who posted online felt that labelling MCA as stemming from a mental disorder served as an excuse for the behavior. The consensus was that the focus should be moved towards the victim.

It is not a physical disorder it is a heinous form of child abuse. It is not something that you have it is something that you do!

Female offenders who perpetrate crimes against children are viewed as more deviant than their male counterparts (17). When MCA maltreatment is discovered, society can exhibit an extreme aversive reaction (18), which the current research confirmed.

They should just be sterilized and removed from society so they can't abuse their children.

Furthermore, all the individuals who reported cases of abuse on the forum noted how the mothers successfully maintained the image of a caring parent to the outside world. This is a key aspect of MCA (10). 
Online perceptions of medical child abuse

She is a master manipulator. She is a pathological liar. She knew all the medical terminology.

She had the doctors wrapped around her little finger.

When the preconceived view of women as loving mothers is combined with the elevated level of deception that these perpetrators present, it sometimes creates resistance toward investigating and confirming suspected cases.

I would like to know HOW you can prove that a mother has this disorder. I have tried everything and no doctor or professional believe me.

The current research demonstrated that when a mother is confronted about her behavior, the maltreatment can escalate as the mother attempts to "prove" how ill the victim is. It is at this point that MCA may become imminently life-threatening (4).

My mother might have escalated her abuse... because she was confronted that she felt the need to change her tactics to meet her needs.

Numerous individuals online compared the actions of a MCA perpetrator to male child-sex offenders, though no sexual offenses against children were mentioned in the cases.

Men who are child molesters have been sterilized so that they can no longer hurt anyone.

That same concept can be applied to these women.

Perpetrator Justice

As suggested above, one of the most interesting findings from the current research was the social perception of appropriate justice. Most individuals felt that a prison sentence was too lenient for 
Online perceptions of medical child abuse

a perpetrator of MCA. Indeed, the main view of justice was the idea of forcibly preventing these women from having any more children through court-ordered hysterectomies.

I believe that this woman should be ordered to have a hysterectomy.

A smaller group of commenters stated that, regardless of the perpetrators' offenses, forced hysterectomy is inhumane. Interestingly, these individuals opposed 'inhumane' treatment of these offenders, yet the level of punishment that they advocated was disproportionate to the crime when compared to the treatment of men who commit similar offenses.

This topic upsets us all, makes us sick. However, we cannot demand a hysterectomy by the courts.

A few individuals felt that, in cases of severe and/or fatal MCA, the perpetrator should receive the death penalty. These comments were driven directly from the case presented by Dr Phil, but generalized to all perpetrators of MCA. Arguably, this could be the result of cultural acceptance of the death penalty as practiced in some states in the U.S., so further investigation would be required.

Does Momma deserve a hysterectomy??? Nope, give her the death penalty.

\section{Causation}

There was a strong belief that the etiology of MBP is simply explained: the perpetrators are inherently evil.

This lady is evil. No other reason for her behaviour.

A small number of individuals felt that there may be a heritable component. 
Online perceptions of medical child abuse

I can readily believe that MBP would be passed on to the next generation because that was the ONLY time my mother showed me and any of us kids any warmth.

While no genetic links or abnormalities have been demonstrated in the brains of people who engage in or endure MCA (19), the research is dated. More recent research into non-specific child abuse has found cases in which two children who have experienced the same pattern of early abuse had different outcomes. This difference could certainly be caused by different psychological factors; however, it is plausible that different outcomes can be affected by a genetic component (20).

\section{Motivation}

Three main motivations were found, previous experiences of abuse; manipulation; and attention-seeking. The last two were deemed selfish reasons for personal gratification, such as being viewed as a hero by medical professionals.

I felt sick to my stomach that a mother could need attention so badly that she could injure her children.

Motivation theory has found enjoyment to be a strong reason for individuals to induce sickness in themselves, and that the adrenaline "rush" of receiving hospital treatment was significant enough to encourage a cycle of implementing illness in oneself (21). The current research found this to be a likely motivation in MCA as well. The next factor considered to be an important motivation was control, either because the perpetrators lacked control in other aspects of their lives or because they gain gratification from the deceitful stories of heroism they tell.

Her actions serve to maintain this sense of power and control. 
Online perceptions of medical child abuse

The use of language such as "creep" makes it clear that the social perception of these women is largely that they are monster-like creatures. Society struggles to comprehend their actions, and dehumanizing them makes it easier to isolate them from the normal social group of mothers.

This lady is crazy. I don't see how this creep could do this to a child.

The final motivation for the behavior was that perhaps the perpetrators themselves had suffered abuse as children and that they were following a pattern they had always known (18). This theory, also referred to as the "victim-to-offender cycle" (22), demonstrates pattern of perpetrators of abuse having been the victims of abuse during childhood.

Usually, the abuser grew up feeling unloved and unwanted, usually the victim of some form of abuse themselves.

\section{Discussion}

The Internet has been used for almost three decades as a safe forum for anonymous access to victim support forums. It offers unprecedented opportunities for people with histories of abuse to seek like-minded individuals and support. Utilizing these open-access forums for research could increase knowledge on this heavily under-researched area to allow clinicians to be more equipped to identify potential cases. However, though the use of the Internet for research is a valuable tool, there is some imprecise - if not flatly untrue--data in online support and self-help groups. In recent years there have been several cases where individuals have been exposed for faking cancer, sexual assaults, and even deaths on Internet forums in attempts to gain attention in a pattern termed, "Munchausen by Internet" $(23,24)$. Thus, while the Internet does provide a positive domain it also harbors a darker side.

Having explored the social perceptions of MCA, it remains clear that individuals view female perpetrators of abuse as "worse" than male counterparts. To move forward, researchers need to 
Online perceptions of medical child abuse

consider the deeper reasoning behind why these women violate what is deemed a natural nurturing instinct. While theories of other forms of child abuse could be applied, the fact that the mother appears to relish being perceived as a "savior" shows that the psychological reasons for the abuse are more complicated. It is imperative that the same amount of research be dedicated to female perpetrators of child maltreatment as is produced for male offenders. In turn, this commitment would allow society, without being overshadowed by disbelief, to understand the warning signs of what makes an individual turn to MCA.

\section{Limitations}

Subjectivity limits qualitative studies, with an overriding concern regarding researcher bias. Aside from potential bias, the major limitation of the study is the restricted scope of its research sample. Although generalization was not the intended goal of the study, the choice of only one forum for analysis created a limitation in the reach to other individuals who might voice their opinions online. Also, it is impossible to assess the validity of each individual post, and there remains the possibility of individuals using the forum to present a false version of themselves (21).

\section{Conclusion}

Now that we have performed the first research into the social perceptions of MCA, it is apparent that many individuals view female perpetrators as far worse than the male partnersincluding those who may have "turned a blind eye." To move forward, investigators need to consider the deeper reasoning behind why these women violate what is deemed a natural, nurturing instinct for their children. While theories related to other forms of child abuse could be applied, the fact that the mother appears to relish being a "savior" shows that the psychological reasons for the abuse are particularly complicated, and may even be specific to MCA. At the same time, research has been constrained by those who refuse to believe that this potentially-devastating form of maltreatment even occurs. They may not only disregard the warning signs of MCA, but not provide victims with any secure networks of support. Overall, our research has provided insights into the possibilities that the 
Online perceptions of medical child abuse

Internet provides for little-known disorders such as MCA, and highlighted significant gaps in current research. 
Online perceptions of medical child abuse

\section{References}

1. American Psychiatric Association. Diagnostic and statistical manual of mental disorders. 5th ed. Arlington, VA: American Psychiatric Association, 2013.

2. Feldman MD. Munchausen by proxy and malingering by proxy. Psychosomatics 2004;45(4):365-6.

3. Truman TL, Ayoub CC. Considering suffocatory abuse and Munchausen by proxy in the evaluation of children experiencing apparent life-threatening events and sudden infant death syndrome. Child Maltreat 2002;7(2):138-48.

4. Beard KV. Protect the children: be on the lookout for Munchausen by proxy. RN 2007;70(12):33-6.

5. Fisher GC, Mitchell I. Is Munchausen syndrome by proxy really a syndrome? Arch Dis Child 1995;72(6):530-4.

6. Fulton D. Early recognition of Munchausen by proxy. Crit Care Nurs Q 2000;23(2):35-42.

7. Shaw RJ, Dayal S, Hartman JK, DeMaso DR. Factitious disorder by proxy: pediatric condition falsification. Harv Rev Psychiatry 2008;16(4):215-24.

8. Schreier HA, Libow JA. Hurting for love: Munchausen by proxy syndrome. New York, NY: The Guilford Press, 1993.

9. Storrs E. Our scapegoat: an exploration of media representations of Myra Hindley and Rosemary West. Theology and Sexuality 2004;11(1):9-28.

10. Schreier H. Munchausen by proxy. Curr Probl Pediatr Adolesc Health Care 2004;34(3):12643. 
Online perceptions of medical child abuse

11. Smith C, Wincup EL. Gender and crime. In: Hale C, Hayward K, Wahidin A, Wincup E, editors. Criminology. Oxford, U.K.: Oxford University Press, 2009;385-405.

12. Mihas P. Load-bearing codes: coding the connections. In: Saldana, J, editor. Tenth International Congress of Qualitative Inquiry; 2014 May 22; Urbana, IL: Sage Publications, 2016;119-127.

13. Miles MB, Huberman AM, Saldana J. Qualitative data analysis: a methods sourcebook. 3rd ed. Thousand Oaks, CA: Sage, 2013.

14. Awadallah N, Vaughan A, Franco K, Munir F, Sharaby N, Goldfarb J. Munchausen by proxy: a case, chart series, and literature review of older victims. Child Abuse Negl 2005;29(8):931-41.

15. Denov MS. The long-term effects of child sexual abuse by female perpetrators: a qualitative study of male and female victims. J Interpers Violence 2004;19(10):1137-56.

16. Morrell B, Tilley DS. The role of non-perpetrating fathers in Munchausen syndrome by proxy: a review of the literature. J Pediatr Nurs 2012;27(4):328-35.

17. Libow JA. Munchausen by proxy victims in adulthood: a first look. Child Abuse Negl 1995;19(9):1131-42.

18. Bexson L. The ultimate betrayal - female child sex offender. Internet Journal of Criminology 2011;4(2):21-34.

19. Jaghab K, Skodnek KB, Padder TA. Munchausen's syndrome and other factitious disorders in children: case series and literature review. Psychiatry (Edgmont) 2006;3(3):46-55.

20. McCrory E, Viding E. Research review: the neurobiology and genetics of maltreatment and adversity. J Child Psychol Psychiatry 2010;51(10):1079-95. 
Online perceptions of medical child abuse

21. Lawlor A, Kirakowski J. When the lie is the truth: grounded theory analysis of an online support group for factitious disorder. Psychiatric Res 2014;218(1-2):209-18.

22. Boyd C, Bromfield L. Young people who sexually abuse: key issues. Australian Institute of Family Studies 2006;1:14-22.

23. Feldman MD. Munchausen by Internet: detecting factitious illness and crisis on the Internet. South Med J 2000;93(7):669-72.

24. Feldman MD, Peychers ME. Legal issues surrounding the exposure of "Munchausen by Internet". Psychosomatics 2007;48(5):451-2. 